\title{
Failure of ORCID: 57 academics named "Beatriz"
}

\author{
Jaime A. Teixeira da Silva ${ }^{1^{*}}$
}

\section{AFFILIATION:}

1. Jaime A. Teixeira da Silva

Independent Researcher

P. O. Box 7, Miki-cho post office, Ikenobe 3011-2,

Kagawa-ken, 761-0799, Japan; jaimetex@yahoo.com

\section{Article info.}

Received: 7 June 2020

Accepted: 18 June 2020

Volume: Vol-10, Issue-2 October, 2020

DOI: https://doi.org/10.3329/updcj.v10i2.50172

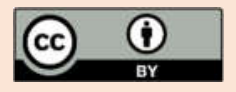

(c) Authors retain copyright and grant the journal right of first publication with the work simultaneously licensed under Creative Commons Attribution License CC - BY 4.0 that allows others to share the work with an acknowledgment of the work's authorship and initial publication in this journal.

https://creativecommons.org/licenses/by/4.0/

Publisher: Update Dental College, Dhaka, Bangladesh

Web: www.updatedentalcollege.edu.bd

E-mail: updcj@hotmail.com

* Corresponding Author

Jaime A. Teixeira da Silva

Independent Researcher

P. O. Box 7, Miki-cho post office, Ikenobe 3011-2,

Kagawa-ken, 761-0799, Japan; jaimetex@yahoo.com

\section{9) Citation}

Jaime A. Teixeira da Silvä. Failure of ORCID: 57 academics named "Beatriz". UpDCJ;10(2):3-5

DOI: https://doi.org/10.3329/updcj.v10i2.50172
A recent editorial by Dr. Md. Ashif Iqbal made an appeal to researchers to adopt ORCID (Open Researcher and Contributor ID), noting that such a system will allow for the accurate identification of an author. ${ }^{1}$ Since authorship is a central factor in academic publishing, the call by Dr. Iqbal on academics to adopt ORCID is not unreasonable and was based on seven benefits, summarized as: 1) a unique number for a unique author, for credit measurement; 2) discoverability of that author's work; 3) a permanent, life-long identifier; 4) a database connector; 5) multidisciplinary and community-based; 6) a supportive research tool; 7) a measure of repute if all authors of a paper have an ORCID. At face value, these benefits cannot be denied, making ORCID an attractive support tool for authors, journals and publishers alike. Since 2012, when ORCID was launched, the number of ORCID accounts is close to 9 million, a veritably impressive number for any new publishing-related system. Even more impressive is the way in which many journals and publishers are not only embracing ORCID, but making it mandatory for authors when they submit a manuscript. Some have gone so far as to refer to ORCID as the building blocks of research infrastructure ${ }^{2}$, suggesting that ORCID has become a key aspect of academic publishing's infrastructure and integrity backbone.

The appeal made by Dr. Iqbal is bold but has value only if the following principles are true and valid: 1 ) the rights of authors are not infringed upon and they have the freedom of choice to select to have an ORCID, or not; 2) all ORCID accounts are valid and complete, i.e., the names, affiliations and academic records are accurate, updated and complete; 3 ) there are no fake, untrustworthy or ambiguous ORCID accounts that could invalidate this tool, the ORCID platform, or other ORCID users. One way to test the validity of ORCID is by assessing fake elements, which are increasing in publishing. ${ }^{3}$ To test this possibility, the ORCID of a potentially fake author, Beatriz Ychussie, was searched on ORCID, based on the information provided in a recent retraction note of an indexed Springer Nature journal, Fixed Point Theory and Applications. Additional clues were gathered from a Retraction Watch blog post and a PubPeer search. At ResearchGate, seven publications, including three retraction notices, are listed for Beatriz Ychussie, who is incorrectly/falsely affiliated with Roskilde University in Denmark. If this author does not exist, and if open access article process costs were paid to SpringerOpen, then who exactly paid those fees?

The ORCID search yielded 8420 results (Jun 4, 2020), a similar number to when only the name "Beatriz" was searched (yielding 8415 results). In other words, no author, 
with a unique name of Beatriz Ychussie, was found on the ORCID database.

More importantly, 57 academics/authors, who were registered at ORCID with only the first name "Beatriz", were discovered. In all cases, no last/family names were listed, and except for one entry, no affiliations were listed. In other words, ORCID lists 56 academics and/or authors that are simply listed as "Beatriz". Relatively speaking, from among the 8420 possible "unique" individuals, the 57 "Beatriz" only account for $0.67 \%$ of the sampled population. Each of those 57 ORCID accounts was accessed to gain as much background information as possible, and a Google as well as a Google Scholar search was made with the ORCID number to determine if the ORCID was associated with any publication, and to thus attempt to find identifiers for any of the 57 "Beatriz" ORCID accounts to assess if any of those accounts were valid.

A detailed examination of the 57 "Beatriz" ORCID accounts revealed that $48(84 \%)$ were labelled with the notice "No public information available." In these accounts, 3 (6\%), 15 (31\%) and 15 (31\%) were last modified in 2018, 2019, and 2020 , respectively, the remainder $(15(31 \%))$ in 2017 or earlier (Table 1). It is unclear why these accounts were modified, what information was modified, and by whom.

Of the 57 "Beatriz" ORCID accounts, the same 48 (84\%) (Table 1) did not link to any publication through a Google/Google Scholar search, and so neither the family name or the affiliation of these "academics" or "authors" could be definitively identified. In 9 (16\%) of "Beatriz" ORCID accounts, the ORCID was associated with publications or other sources of academic/author validation, so the tentative correct identity of these nine "Beatriz" was tentatively resolved. However, even though these individuals could be tracked, this involved doing an independent investigation of several websites, thus defeating the purpose of having an ORCID, i.e., to verify the publishing record, or to authenticate the author using this tool. If anything, ORCID has complicated the issue of author identification and verification. Two "positive controls" (valid ORCID accounts linked to veritable scientists with independently verifiable publications linked to the ORCIDs) were used of reputable academics linked to publishing and library and/or information sciences: John P.A. loannidis (Stanford University, USA), and David Moher (Ottawa Hospital Research Institute, Canada).

Since ORCID is being passionately promoted as a tool of integrity, and a support of academic publishing's integrity, it is very important to identify false, inaccurate or incomplete elements of ORCID that may disqualify it as an effective tool of integrity, as well as author validation and identification. This small case study identified, through the attempted identification of a potentially fake author, 57 ORCID accounts for which only a first name was listed, "Beatriz", 48 of which are completely unknown or untraceable entities. This demonstrates that: 1) at least 57 academics/authors with the name "Beatriz" do not have a unique name, even though they may have a unique ORCID; 2) the ORCID database is being populated with accounts that are incomplete, or that may carry false or fake academics. Somebody must have created those accounts, and those individuals or groups should be held accountable. What percentage of the 8.7 million ORCID accounts are fake, empty, unpopulated ("ghost" accounts) or otherwise untrustworthy?

Table 1 List of ORCID accounts for 48 "Beatriz" for which no family name, no affiliation, and no association with any publication could be identified

\begin{tabular}{|c|c|c|}
\hline First name* & ORCID account & Record last modified* \\
\hline Beatriz & $\underline{0000-0002-3173-7414}$ & $2019 / 10 / 2420: 55$ \\
\hline Beatriz & $\underline{0000-0002-0381-0039}$ & $2019 / 11 / 317: 14$ \\
\hline Beatriz & $\underline{0000-0002-1858-8506}$ & $2019 / 12 / 102: 08$ \\
\hline Beatriz & $\underline{0000-0002-4554-7507}$ & $2019 / 4 / 82: 18$ \\
\hline Beatriz & $\underline{0000-0001-8480-4150}$ & $2019 / 9 / 2218: 40$ \\
\hline Beatriz & $\underline{0000-0002-3898-9526}$ & $2015 / 12 / 1723: 17$ \\
\hline Beatriz & $\underline{0000-0002-8756-1243}$ & $2019 / 7 / 2421: 26$ \\
\hline Beatriz & $\underline{0000-0002-4074-4798}$ & $2016 / 10 / 2521: 17$ \\
\hline Beatriz & $\underline{0000-0002-0754-0259}$ & $2016 / 9 / 2621: 52$ \\
\hline Beatriz & $\underline{0000-0002-2248-1808}$ & $2016 / 6 / 1422: 10$ \\
\hline Beatriz & $\underline{0000-0001-5671-5548}$ & $2017 / 3 / 620: 29$ \\
\hline beatriz & $\underline{0000-0002-3102-9450}$ & 2019/9/30 13:44 \\
\hline Beatriz & $\underline{0000-0002-2987-6861}$ & 2018/9/30 19:24 \\
\hline Beatriz & $\underline{0000-0002-6608-9082}$ & $2019 / 6 / 516: 36$ \\
\hline Beatriz & 0000-0003-3164-0839 & $2019 / 7 / 313: 15$ \\
\hline Beatriz & 0000-0003-0718-7595 & $2015 / 12 / 1723: 17$ \\
\hline Beatriz & $\underline{0000-0002-0472-0684}$ & $2018 / 9 / 521: 58$ \\
\hline Beatriz & 0000-0001-6054-8068 & 2016/4/10 13:02 \\
\hline Beatriz & $\underline{0000-0003-2478-3102}$ & $2016 / 9 / 1517: 59$ \\
\hline Beatriz & 0000-0003-0687-107X & $2016 / 6 / 150: 47$ \\
\hline BEATRIZ & $\underline{0000-0002-0699-7951}$ & $2016 / 6 / 150: 41$ \\
\hline BEATRIZ & $\underline{0000-0002-5554-4406}$ & $2016 / 6 / 15$ 0:09 \\
\hline Beatriz & $\underline{0000-0002-2322-2883}$ & $2017 / 1 / 1014: 58$ \\
\hline Beatriz & $\underline{0000-0002-9835-037 \mathrm{X}}$ & $2020 / 1 / 30: 11$ \\
\hline Beatriz & $\underline{0000-0003-1583-8829}$ & $2020 / 2 / 1717: 36$ \\
\hline Beatriz & $\underline{0000-0003-4851-5583}$ & $2019 / 10 / 237: 40$ \\
\hline Beatriz & $\underline{0000-0002-3585-1599}$ & $2019 / 8 / 2310: 18$ \\
\hline Beatriz & $\underline{0000-0002-4838-7609}$ & $2016 / 6 / 1421: 22$ \\
\hline Beatriz & 0000-0003-3143-2597 & $2016 / 7 / 276: 14$ \\
\hline Beatriz & $\underline{0000-0002-4954-4223}$ & 2019/6/21 23:19 \\
\hline Beatriz & $\underline{0000-0001-8814-8568}$ & $2020 / 5 / 414: 03$ \\
\hline Beatriz & $\underline{0000-0003-1527-4330}$ & $2020 / 2 / 1321: 25$ \\
\hline Beatriz & $\underline{0000-0002-9160-4680}$ & $2019 / 4 / 2518: 48$ \\
\hline Beatriz & $\underline{0000-0002-8599-7801}$ & 2019/7/16 11:26 \\
\hline Beatriz & 0000-0003-0149-6928 & $2018 / 2 / 522: 26$ \\
\hline Beatriz & $\underline{0000-0002-5111-3967}$ & $2019 / 8 / 1213: 39$ \\
\hline Beatriz & $\underline{0000-0002-5477-8614}$ & $2017 / 10 / 18$ 0:24 \\
\hline BEATRIZ & $\underline{0000-0002-1072-1026}$ & $2020 / 1 / 1816: 33$ \\
\hline Beatriz & $\underline{0000-0003-3979-0225}$ & $2020 / 1 / 2118: 50$ \\
\hline BEATRIZ & $\underline{0000-0003-3154-7562}$ & $2020 / 1 / 919: 56$ \\
\hline Beatriz & $\underline{0000-0001-7534-2724}$ & $2020 / 3 / 1111: 18$ \\
\hline Beatriz & $\underline{0000-0002-7233-3141}$ & $2020 / 5 / 2723: 49$ \\
\hline Beatriz & $\underline{0000-0002-8394-1281}$ & $2020 / 3 / 3018: 35$ \\
\hline Beatriz & $\underline{0000-0002-4739-0152}$ & $2020 / 4 / 2021: 55$ \\
\hline Beatriz & $\underline{0000-0003-1080-4793}$ & $2020 / 4 / 1213: 32$ \\
\hline Beatriz & $\underline{0000-0002-7054-7517}$ & 2020/5/13 21:11 \\
\hline Beatriz & $\underline{0000-0001-6205-7596}$ & $2020 / 6 / 222: 19$ \\
\hline Beatriz & $\underline{0000-0002-5052-9346}$ & $2020 / 6 / 1 \quad 10: 45$ \\
\hline
\end{tabular}

Although this is only a single case study, which may be perceived as a limitation, it does show that there are practical problems, and risks, associated with ORCID. These aspects Website: https://www.banglajol.info/index.php/UpDCJ 
reduce trust in ORCID, and decrease its reliability as a publishing tool or integrity platform. The existence of such accounts represents failure in quality control by ORCID, who seem more interested in increasing the numbers without carefully analyzing the details of new accounts. As a result of quality oversight, ORCID is now in a quandary and serious predicament: if they cut any ORCID account for being a fake or "ghost" author, then this organization will be perceived as being able to manipulate the public record, and if it leaves these indiscernible accounts as they are, then it leaves the public record corrupted and unreliable. This also poses a challenge to Retraction Watch, which currently lists this fake author, Beatriz Ychussie, who simply cannot be held accountable, on its retraction database.

\section{Conflicts of interest and disclaimer}

The author does not have, nor wishes to have, given the risks detected, an ORCID account. On May 18, 2020, the author contacted the Filomat editors by email to inquire about the validity of authorship of Beatriz Ychussie in a Filomat paper. The Filomat editors have initiated an investigation. The author has profiled, and has been profiled, by PubPeer and Retraction Watch. The author declares no relevant conflicts of interest related to this topic.

\section{Declarations}

Funding: Not applicable. Ethics approval: Not applicable. Availability of data and material: Available in paper. Code availability: Not applicable. Author's contributions: The author conceived the idea, conducted all analyses and investigations, and developed all drafts of the paper. Consent for publication: Not applicable.

\section{REFERENCES:}

1. Iqbal MA. ORCID Identification: Importance as a researcher. Update Dental College Journal,9(2) 2019 1-2.https://doi.org/10.3329/updcj.v9i2.43730

2. Meadows A, Haak L L, Brown J. Persistent identifiers: the building blocks of the research information infrastructure. Insights, 32(1) (2019) 9. https://doi.org/10.1629/uksg.457

3. Teixeira da Silva J A. Fake peer reviews, fake identities, fake accounts, fake data: beware! AME Medical Journal, 2 (2017) 28.

https://doi.org/10.21037/amj.2017.02.10 